\title{
From concept to in vivo testing: Microcontainers for oral drug delivery
}

Mazzoni, Chiara; Tentor, Fabio; Andersen, Sophie Strindberg; Nielsen, Line Hagner; Keller, Stephan Sylvest; Alstrøm, Tommy Sonne; Gundlach, Carsten; Müllertz, Anette; Marizza, Paolo; Boisen, Anja

Published in:

Journal of Controlled Release

Link to article, DOI:

10.1016/j.jconrel.2017.10.013

Publication date:

2017

Document Version

Peer reviewed version

Link back to DTU Orbit

Citation (APA):

Mazzoni, C., Tentor, F., Andersen, S. S., Nielsen, L. H., Keller, S. S., Alstrøm, T. S., Gundlach, C., Müllertz, A., Marizza, P., \& Boisen, A. (2017). From concept to in vivo testing: Microcontainers for oral drug delivery. Journal of Controlled Release, 268, 343-351. https://doi.org/10.1016/j.jconrel.2017.10.013

\section{General rights}

Copyright and moral rights for the publications made accessible in the public portal are retained by the authors and/or other copyright owners and it is a condition of accessing publications that users recognise and abide by the legal requirements associated with these rights.

- Users may download and print one copy of any publication from the public portal for the purpose of private study or research.

- You may not further distribute the material or use it for any profit-making activity or commercial gain

- You may freely distribute the URL identifying the publication in the public portal 


\section{From concept to in vivo testing: Microcontainers for oral drug delivery}

Chiara Mazzoni ${ }^{1=*}$, Fabio Tentor ${ }^{1=*}$, Sophie Strindberg Andersen ${ }^{2}$, Line Hagner Nielsen ${ }^{1}$, Stephan Sylvest Keller ${ }^{1}$, Tommy Sonne Alstrøm ${ }^{3}$, Carsten Gundlach ${ }^{4}$, Anette Müllertz $^{2}$, Paolo Marizza ${ }^{1}$, Anja Boisen ${ }^{1}$

=The authors contributed equally to the work.

*Corresponding authors

${ }^{1}$ Department of Micro- and Nanotechnology, Technical University of Denmark, Ørsteds Plads 345C, 2800 Kgs. Lyngby, Denmark

${ }^{2}$ Department of Pharmacy, Faculty of Health and Medical Sciences, University of Copenhagen, Universitetsparken 2, 2100 Copenhagen O, Denmark

${ }^{3}$ Department of Applied Mathematics and Computer Science, Technical University of Denmark, Richard Petersens Plads 324, 2800 Kgs. Lyngby, Denmark

${ }^{4}$ Department of Physics, NEXMAP, Technical University of Denmark, Fysikvej 311, 2800 Kgs. Lyngby, Denmark

Keywords: enteric coating; supercritical impregnation; oral drug delivery; microtechnology 


\begin{abstract}
This work explores the potential of polymeric micrometer sized devices (microcontainers) as oral drug delivery systems (DDS). Arrays of detachable microcontainers (D-MCs) were fabricated on a sacrificial layer to improve the handling and facilitate the collection of individual D-MCs. A model drug, ketoprofen, was loaded into the microcontainers using supercritical $\mathrm{CO}_{2}$ impregnation, followed by deposition of an enteric coating to protect the drug from the harsh gastric environment and to provide a fast release in the intestine. In vitro, in vivo and ex vivo studies were performed to assess the viability of the D-MCs as oral DDS. D-MCs improved the relative oral bioavailability by $180 \%$ within $4 \mathrm{~h}$, and increased the absorption rate by 2.4 times compared to the control. This work represents a significant step forward in the translation of these devices from laboratory to clinic.
\end{abstract}




\section{Introduction}

Oral administration of drugs is preferred by patients ${ }^{1}$ due to its inherently reduced invasiveness compared to injections and minimal need for trained personnel ${ }^{2,3}$. Moreover, the effective healthcare costs can be diminished avoiding the usage of drugs administered by injections ${ }^{4,5}$.

Following oral administration, drug absorption will occur in the gastro-intestinal (GI) tract; primarily in the small intestine due to a high surface area provided by the presence of villi and microvilli ${ }^{6,7}$. When delivering drugs through the GI tract, care needs to be taken due to the presence of enzymes and a low gastric $\mathrm{pH}(1-3.5$ in fasted state and $3-6$ in fed state $)^{8}$. Both of these can have a negative impact on the administered drug, thereby limiting the effect of the oral formulation.

Traditional oral dosage forms, such as tablets or capsules, can be designed to target the intestine. Enteric coatings can be used to protect the dosage form during transit of the stomach and facilitate the delivery of the drug to the intestinal epithelium for systemic absorption ${ }^{9,10}$. Tablets, capsules as well as micro- and nanoparticulate systems (i.e. vesicles, polymeric particles and dendrimers) ${ }^{11,12,13}$, manifest an omni-directional release of the drug in the intestinal lumen. Omni-directional release entails an inevitable loss of the drug in the lumen and therefore a reduction of the drug absorbed into the systemic circulation. Recent and promising approaches focus on reservoir-based microdevices serving as drug carriers, potentially bringing the drug to the desired place of absorption by unidirectional release from the device. An example of such microdevices is microcontainers. Here a polymeric cylinder is situated on a flat surface, defining a container structure with a cavity in the micrometer size ${ }^{14,15}$. Microcontainers provide unidirectional drug release due to their design and a protection of the drug formulation from the acidic environment of the stomach. Previously, they have been suggested as a promising oral drug delivery system, for instance maintaining indomethacin in its amorphous state $^{16,17}$ and being suitable for the confinement of spray dried lipid nanoparticles ${ }^{18}$. Furthermore, microcontainers have shown to improve the oral bioavailability of an amorphous salt of furosemide (a class IV drug in the Biopharmaceutics Classification System (BCS)), compared to the same drug loaded into a capsule. It was speculated by the authors that this could be due to the protection of the drug during the passage through the stomach and because of an engulfment of the microcontainers in the intestinal mucus, resulting in a prolonged absorption period ${ }^{19}$. Chirra et al. have illustrated the beneficial effect of using microdevices to improve the relative oral bioavailability of the BCS class III drug, acyclovir compared to a solution of the same drug ${ }^{20}$. Moreover, Fox et al. have shown that nanostraw membranes (porous nanostructured delivery substrates) increase adhesion to the mucus and facilitate the drug loading via diffusion ${ }^{21}$. So far, the presented works have only covered part of a device development and/or characterization and in most cases not reporting on in vivo studies, and not characterizing the devices and drugs after individual processing steps. For example, we have previously reported on drug loading of polymer filled microcontainers using supercritical carbon dioxide $\left(\mathrm{scCO}_{2}\right)^{22}$. However, these containers were not detachable and thus, never used in animal studies. Likewise, we have reported on microcontainers loaded with powder of furosemide ${ }^{19}$ where the filled containers were mechanically removed from the carrier substrate introducing a risk of damaging the containers.

Here we present, for the first time, the complete process of developing and characterizing a microcontainerbased oral delivery system. The aim of this work was to translate detachable microcontainers (D-MCs) filled with drug and sealed with a lid, from the concept to the final oral DDS suitable for in vivo and ex vivo studies. For this purpose, D-MCs have been fabricated on a sacrificial layer, improving handling and facilitating detachment and collection of the individual filled and coated D-MCs. D-MCs were loaded with the BCS class II model drug ketoprofen utilizing $\mathrm{scCO}_{2}$ followed by an enteric coating to prevent release of the formulation during handling, detachment and transit through the stomach. The loaded and coated D-MCs were investigated in vitro to assess the functionality of the enteric lid, and in vivo and ex vivo, to evaluate the potential of microcontainers as an oral DDS. 


\section{Materials and methods}

\section{Fabrication of detachable microcontainers (D-MCs)}

Silicon (Si) wafers (4-in. b100N n-type) were supplied by Okmetic (Vantaa, Finland). SU-8 2075 and SU-8 developer were purchased from Microresist Technology GmbH (Berlin, Germany). Polyacrylic acid 35 wt \% aqueous solution (PAA, Mw 100,000) was purchased from Sigma Aldrich (St. Louis, USA) and neutralized with $\mathrm{NaOH}$. A $15 \mu \mathrm{m}$ thick film of PAA was spin coated on a Si wafer and dried at $80^{\circ} \mathrm{C}$ for $10 \mathrm{~min}$. The PAA film served as a water soluble release layer after completed detachable microcontainers (D-MCs) fabrication ${ }^{23}$. DMCs were fabricated with epoxy-based photoresist SU-8 using a procedure similar to the one described earlier ${ }^{15,16}$. After fabrication, the wafers were cut into square chips containing $625 \mathrm{D}$-MCs using a laser (microSTRUCT vario, 3D Microac AG, Chemnitz, Germany). The dimensions of the D-MCs were measured using an Alpha-Step IQ Stylus Profilometer (KLA-Tencor Corporation, Milpitas, USA) and optical microscopy.

\section{Loading of drug formulation into the microcontainers}

D-MCs sitting on a Si chip were manually loaded with polyvinylpyrrolidone (PVP) (Mw = 10,000, Sigma Aldrich, St. Louis, USA) blowing away the excess in between the D-MCs using an air gun in a similar setup as described previously ${ }^{18,19}$. The chips were weighted before and after and placed within a supercritical $\mathrm{CO}_{2}$ chamber ( 3 chips at a time, see Figure 1), together with $14.2 \pm 0.1 \mathrm{mg}(\mathrm{n}=15, \mathrm{SD})$ of ketoprofen powder $(\geq 98$ $\%$ racemate, Sigma Aldrich, St. Louis, USA). The impregnation of the polymer was conducted by bringing $\mathrm{CO}_{2}$ over its supercritical state at 100 bar and $40{ }^{\circ} \mathrm{C}$, keeping it under stirring for $1 \mathrm{~h}$. During this process ketoprofen solubilizes in supercritical $\mathrm{CO}_{2}$ and diffuses into the polymer matrix. The pressurization and depressurization rate were $3.9 \mathrm{bar} / \mathrm{min}$ and $2.5 \mathrm{bar} / \mathrm{min}$, respectively.

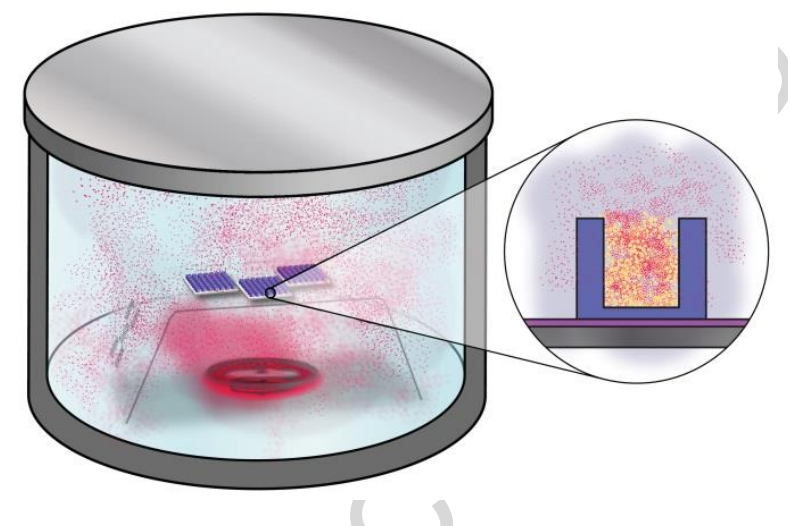

Figure 1: Schematic representation of the supercritical $\mathrm{CO}_{2}$ impregnation process. Within the chamber the loading of three $\mathrm{D}$-MCs chips due to the solubilization of ketoprofen in the supercritical $\mathrm{CO}_{2}$ is depicted. On the right, a zoom in of one $\mathrm{D}$-MC during the loading process is represented.

\section{Enteric coating deposition}

A pH sensitive polymer, Eudragit ${ }^{\circledR}$ L100 (Evonik, Darmstad, Germany) was employed for the enteric coating on the cavity of the D-MCs. A solution of $2 \% \mathrm{w} / \mathrm{v}$ Eudragit ${ }^{\circledR} \mathrm{L} 100$ and $5 \% \mathrm{w} / \mathrm{w}$ in relation to the polymer of dibutyl sebacate (Sigma Aldrich, St. Louis, USA) was dissolved in isopropanol (Sigma Aldrich, St. Louis, USA).

The solution was sprayed over a chip of drug-loaded microcontainers using an ultrasonic spray coater equipped with an accumist nozzle operating at $120 \mathrm{kHz}$ (Sono-Tek, USA). During the procedure, the flow rate was kept at 
$0.1 \mathrm{~mL} / \mathrm{min}$, together with a $1.5 \mathrm{~W}$ generator power. The shaping air was set to $0.02 \mathrm{bar}$, and the speed of the nozzle was maintained at $5 \mathrm{~mm} / \mathrm{sec}$, keeping a distance between the tip and the sample of $6.5 \mathrm{~cm}$. The nozzle of the spray coater was positioned above the chip containing loaded D-MCs, following a path in the $\mathrm{x}-\mathrm{y}$ axis to cover an area defined by the corners of the chip, previously identified using an integrated camera. Each chip was coated with two alternating wavy line spray paths having an offset of $2 \mathrm{~mm}$, resulting in a total of 100 passages. The chips were kept at $40^{\circ} \mathrm{C}$ during the spray coating process.

\section{Morphology characterization}

X-ray micro computed tomography (X-ray $\mu \mathrm{CT}$, Zeiss Xradia 410 versa, Pleasanton, USA) was applied to assess the filling level of the ketoprofen:PVP formulation into the D-MCs and the coating morphology on the cavity of the D-MCs. The 3D tomographic reconstruction was done with the software, provided with the system, based on a FDK algorithm ${ }^{24}$. The chip with D-MCs was investigated using a high voltage of $60 \mathrm{kV}$ and having an effective pixel size of $19.33 \mu \mathrm{m}$, taking 1601 projection images. For examining smaller parts of the chip with a higher resolution $60 \mathrm{kV}$ as high voltage and an effective pixel size of $3.02 \mu \mathrm{m}$ with 3201 projection images was utilized. Three areas from each sample were analyzed to obtain a more representative image of the whole chip. Capsules filled with D-MCs were scanned to assess the effect of the collection of the D-MCs after their detachment, to assess if they were separated one to each other and if the coating was still intact. For this purpose, scans were recorded with a voltage of $40 \mathrm{kV}$ with a pixel size of either $10.23 \mu \mathrm{m}$ or $3.36 \mu \mathrm{m}$, taking 1601 projection images.

The quality of both the loading and the coating of the D-MCs was investigated using a Zeiss Supra 40VP Field Emission Scanning Electron Microscope (SEM, Carl Zeiss Microscopy GmbH, Jena, Germany). The samples were placed over metallic holders and tilted to $30^{\circ}$ prior the analyses, both low and high vacuum modes were used with a variable energy between 4 and $8 \mathrm{keV}$.

The coating thickness of Eudragit ${ }^{\circledR}$ L100 was measured by contact profilometry (Alpha-Step IQ Stylus Profilometer, KLA-Tencor Corporation, Milpitas, USA). Eudragit ${ }^{\circledR}$ L100 films were sprayed on a SU-8 covered flat silicon chip as described in the above section 'Enteric coating deposition'. The profiles were measured using a $15.6 \mathrm{mg}$ tip force with a scan speed of $20 \mu \mathrm{m} / \mathrm{sec}$ and a sampling rate of $50 \mathrm{~Hz}$.

\section{Solid state characterization of ketoprofen}

X-Ray powder diffraction (XRPD) was used to determine the solid state form of ketoprofen in the D-MCs and of the controls. An X'Pert PRO X-ray diffractometer (PANalytical, Almelo, The Netherlands, MPD PW3040/60 $\mathrm{XRD}$; $\mathrm{Cu} \mathrm{KR}$ anode, $\lambda=1.541 \AA, 45 \mathrm{kV}, 40 \mathrm{~mA}$ ) was utilized. A starting angle of $5^{\circ} 2 \theta$ and an end angle of $25^{\circ}$ $2 \theta$ were employed for the scans with a scan speed of $0.67335^{\circ} 2 \theta / \mathrm{min}$ and a step size of $0.0262606^{\circ} 2 \theta$. Data were collected using X'Pert Data Collector software (PANalytical B.V.). The diffractogram of loaded and coated D-MCs was compared to that of crystalline ketoprofen, coated D-MCs loaded with crystalline ketoprofen and DMCs loaded with 1:4 crystalline ketoprofen:PVP. The diffractograms of D-MCs on the PAA layer, PVP and Eudragit $^{\circledR}$ L100 were also investigated for comparison (data not shown). Moreover, XRPD was used to verify the amorphous form of ketoprofen in the control samples for the in vivo studies (described in the 'Capsules preparation' section).

In addition, the solid state form of ketoprofen impregnated into the D-MCs and of control formulations was assessed by means of Raman spectroscopy using a DXR Raman microscope (Thermo Fisher Scientific, Inc., Waltham, USA). The microscope was coupled to a single grating spectrometer with $5 \mathrm{~cm}^{-1} \mathrm{FWHM}$ spectral resolution and $\pm 2 \mathrm{~cm}^{-1}$ wavenumber accuracy. All spectra were collected using a laser with a wavelength of 780 $\mathrm{nm}$, with a $50 \times$ objective and an estimated laser spot of $3.6 \mu \mathrm{m}$ diameter. A $50 \mu \mathrm{m}$ slit was utilized when analyzing bulk powder, whereas a $25 \mu \mathrm{m}$ pinhole was deployed to analyze the ketoprofen inside the microcontainers the laser power was equal to 10 and $20 \mathrm{~mW}$, respectively. The spectra of: i) pure ketoprofen, ii) pure PVP and iii) microcontainers filled with PVP and impregnated with ketoprofen were compared. 


\section{Release of ketoprofen from D-MCs}

The efficacy of the coating and its resistance after the detachment of the D-MCs was evaluated determining the release of the impregnated ketoprofen, both in a Fasted State Simulated Gastric Fluid (FaSSGF pH 1.65 Biorelevant $^{\circledR}$, London, UK) and Fasted State Simulated Intestinal Fluid (FaSSIF pH 6.5 - Biorelevant ${ }^{\circledR}$, London, UK). Impregnated chips either coated or uncoated were individually immersed in $2 \mathrm{~mL}$ of deionized water ( $\mathrm{pH}$ 3.25) to allow the solubilization of the PAA layer (avoiding the coating to dissolve) and hence, the detachment of the D-MCs. Suspended D-MCs were transferred into dialysis bags (MW cut off: 14,000) and placed in $20 \mathrm{~mL}$ of FaSSGF in an orbital shaking water bath at $37{ }^{\circ} \mathrm{C}, 150 \mathrm{rpm}$ (Grant Instrument Ltd, model OLS26, Cambridge, UK) for $2 \mathrm{~h}$. Afterwards, the bags were removed, rinsed with FaSSIF and placed in $20 \mathrm{~mL}$ of fresh FaSSIF at 37 ${ }^{\circ} \mathrm{C}, 150 \mathrm{rpm}$ for $6 \mathrm{~h} .20 \mu \mathrm{L}$ were collected at $0,5,10,20,40,60,120$ min during the release in FaSSGF and after 1, 2, 5, 10, 20, 40, 60, 120, 240 and 360 min during the release in FaSSIF. Samples were analyzed using the UVVis spectrophotometer (NanoDrop 2000c, Thermo Fisher Scientific Inc., UK) at $258 \mathrm{~nm}$. The amount of ketoprofen loaded in the D-MCs chips was also investigated as described in the section 'In vitro release of ketoprofen from coated D-MCs'. The release curves were performed at least in triplicates $(\mathrm{n}=3$ for the coated and $\mathrm{n}=6$ for the uncoated D-MCs).

\section{Capsules preparation}

Three chips of D-MCs were impregnated together and coated individually as described above. The solubilization of the sacrificial layer and the subsequent detachment from the Si chip were obtained soaking the chips into 5 $\mathrm{mL}$ of deionized water $(\mathrm{pH} 3.25)$. After $5 \mathrm{~min}$, the water was removed and the $\mathrm{D}$-MCs were dried at $37^{\circ} \mathrm{C}$ for 15 min. Gelatin capsules (Torpac ${ }^{\circledR}$ size 9, Fairfield, USA) were filled with individual D-MCs (258 \pm 31 D-MCs per capsule, as visible in Figure S5 in the Supplementary Information) and weighted before and after filling. The concentration of ketoprofen in the capsules was assessed in vitro by placing 14 capsules in $20 \mathrm{~mL}$ of phosphate buffered saline (PBS, Sigma Aldrich, St. Louis, USA) and kept under stirring (150 rpm) at $37{ }^{\circ} \mathrm{C}$ for $24 \mathrm{~h}$. Measurements were done through UV-Vis spectroscopy as described before at a wavelength of $258 \mathrm{~nm}$.

The preparation for the control for the in vivo study started with a physical mixture of ketoprofen and PVP powders with the same weight ratio $(1: 4)$ as in the D-MCs. The mixture was prepared by heating it up to $120^{\circ} \mathrm{C}$ on a heating plate gently mixing the two compounds during the melting of the drug. The heated mixture was immediately quenched using liquid nitrogen followed by grinding to a fine powder. The amorphous form of ketoprofen was confirmed using XRPD as previously described. Gelatin capsules were loaded with $922.4 \pm 11.5$ $\mu \mathrm{g}$ of the grinded powder, an amount corresponding to that of the D-MCs formulation. Subsequently, the capsules were coated with a solution of $5 \% \mathrm{w} / \mathrm{v}$ Eudragit ${ }^{\circledR} \mathrm{L} 100$ and $5 \% \mathrm{w} / \mathrm{w}$ dibutyl sebacate in relation to the polymer in isopropanol. The capsules were coated by dipping half of it into the coating solution and dried for 15 min before coating the other half. This procedure was repeated three times for each capsule.

\section{In vivo and ex vivo studies}

All animal care and experimental studies were performed according to Danish and European laws, guidelines and policies for animal housing, care and experiments at the University of Copenhagen. The in vivo experiment was carried out at the Department of Experimental Medicine, University of Copenhagen and approved by the local institutional Animal Welfare Committee under the license number 2015-15-0201-00454. The ex vivo study was performed at the Department of Pharmacy, University of Copenhagen under the license number 201615-0201-00892. Both studies were carried out in compliance with the Danish laws regulating experiments on animals and EC Directive 2010/63/EU. 
Male Sprague-Dawley rats were housed in pairs in cages to acclimatize for a period of one week with a light/dark period of $12 / 12 \mathrm{~h}$ and a temperature of $22{ }^{\circ} \mathrm{C}$ with a relative humidity of $55 \pm 10 \%$. During this period, the rats had free access to standard pellets and water.

For the in vivo study the rats with a weight ranging from 373 to $436 \mathrm{~g}$ were randomly divided into two groups. One group was dosed with capsules loaded with $\mathrm{D}-\mathrm{MCs}(\mathrm{n}=11)$, the second group was dosed with capsules containing the control formulation $(n=6)$. Both types of capsules were given using a polyurethane feeding tube (Instech Laboratories Inc., Plymouth Meeting, USA), one capsule was dosed per rat. The rats were fastened for 1 $\mathrm{h}$ before and after the dosing, and for the rest of period they had free access to water and standard pellets. Blood $(200 \mu \mathrm{L})$ was sampled through the lateral tail vein at 15, 30, 45, 60, 75, 90, $120 \mathrm{~min}, 4,6,8$ and $24 \mathrm{~h}$ post dosing and collected in ethylenediaminetetraacetic acid tripotassium salt dihydrate (EDTA, Sigma-Aldrich, St. Louis, USA) coated tubes. Plasma was obtained by immediately spinning the blood samples at 1,500 g for $10 \mathrm{~min}$. Plasma was stored at $-20^{\circ} \mathrm{C}$ until further analyses.

For the ex vivo study, two male Sprague-Dawley rats weighting 316 and $319 \mathrm{~g}$ were used and were fasted $1 \mathrm{~h}$ prior to dosing.

Capsules filled with D-MCs (see the section 'Capsules preparation') were administered to the rats by oral gavage as described previously. After 90 min post-dosing, the rats were sacrificed, and opened at the linea alba for retrieving the stomach and small intestine. These were immediately cut open and examined for localizing the DMCs using a stereo microscope (SteReo Discovery V8, Carl Zeiss MicroImaging GmbH, Jena, Germany).

\section{High Press ure Liquid Chromatography (HPLC) analysis of plasma samples}

HPLC analyses were performed using a Dionex Ultimate 3000 Pump equipped with a Dionex ASI-100 Automated Sample Injector and with a UV-VIS lamp.

Ketoprofen was extracted from the plasma samples using a method described elsewhere ${ }^{25}$ with minor modifications. Briefly, methanol was added in a 3:1 v/v ratio to the plasma and, after vortexing the mixtures, the samples were centrifuged at 15,000 $\mathrm{g}$ for $6 \mathrm{~min}$ and the supernatants were transferred into HPLC vials.

The HPLC was run in isocratic mode using a method already described in literature with slight modifications ${ }^{25}$. The mobile phases constituted of (A): deionized water with $1 \%$ v/v trifluoroacetate (Sigma Aldrich, St. Louis, USA) and (B): $100 \%$ acetonitrile (Sigma Aldrich, St. Louis, USA). The ratio of the mobile phase A:B was equal to $45: 55 \mathrm{v} / \mathrm{v}$. Samples were run over a Kinetex 5.0 $\mu \mathrm{m}$ XB-C18 $100 \AA$ A, 100 x $4.6 \mathrm{~mm}$ column (Phenomenex ApS, Nordic Region, Værløse, Denmark) at $22{ }^{\circ} \mathrm{C}$. The injected volume was $40 \mu \mathrm{L}$ with a flow rate of $1 \mathrm{~mL} / \mathrm{min}$ and a total run time per sample of $10 \mathrm{~min}$. The absorbance was measured at $258 \mathrm{~nm}$.

\section{Statistics}

For the in vivo studies, all results were normalized for the averages of rat mass and of the ketoprofen dosed.

To calculate the standard error for the area under the curve (AUC, Table 1), the standard error of the mean of correlated variables is used

$$
\mathrm{SE}_{\overline{A U C}}=\sqrt{\frac{\sum_{i=1}^{M} \operatorname{var}\left[A_{i}\right]+\sum_{i=1}^{M} \sum_{j \neq i}^{M} \operatorname{cov}\left(A_{i}, A_{j}\right)}{N}}
$$

Where $A_{i}$ is the AUC for region $i$.

To calculate the average amount of PVP inside a capsule, and the associated standard error, the following formula is derived. To derive the formula, it is assumed that the amount of PVP in each D-MCs in the filling process are independently distributed. 


$$
\mathrm{SE}_{\overline{P V P}}=\sqrt{\frac{1}{N_{C}}\left(\frac{1}{N M} \operatorname{var}[X] \operatorname{var}[Y]+\frac{1}{N} \operatorname{var}[X] \mathrm{E}[Y]^{2}+\frac{1}{M} \operatorname{var}[Y] E[X]^{2}\right)}
$$

Where $N_{c}$ is the total amount of microcontainers per chip, $X$ is the total amount of PVP measured $N$ times, and $Y$ is the number of microcontainers contained inside a capsule, measured $M$ times.

The raw data can be found in the Supplementary Information (Figure S4).

Moreover, as the sample sizes are different the effect sizes reported in Table 1 uses the Hedges g effect size defined as $g=\left(M_{1}-M_{2}\right) / S D_{\text {pooled }}$ where $S D_{\text {pooled }}$ is the weighted standard deviation of the two groups ${ }^{26-28}$. All of the data are expressed as mean and the usage of standard deviation (SD) or standard error of the mean (SE) is defined within the text. Where appropriate, statistical analysis was carried out using Student t-tests using GraphPad Prism version 6.05. P-values below $5 \%(\mathrm{p}<0.05)$ were considered statistically significant.

\section{Results}

\section{Fabrication of microcontaine rs on a sacrificial layer}

D-MCs were successfully fabricated in SU-8 on a water soluble layer of PAA. D-MCs had a height of $304 \pm 12$ $\mu \mathrm{m}(\mathrm{n}=8, \mathrm{SD})$ and a diameter equal to $329 \pm 5 \mu \mathrm{m}(\mathrm{n}=8, \mathrm{SD})$. The inner reservoir had a depth of $272 \pm 6 \mu \mathrm{m}$ $(\mathrm{n}=8, \mathrm{SD})$ and a diameter of $188 \pm 4 \mu \mathrm{m}(\mathrm{n}=8$, SD) resulting in a container volume of $7.5 \pm 0.3 \mathrm{~nL}(\mathrm{n}=8$, SD). D-MCs were adhering well to the PAA layer not impairing the handling. D-MCs were arranged in arrays of $25 \times 25$ devices on quadratic chips with a side length of $12.8 \mathrm{~mm}$.

\section{Loading of D-MCs}

Every chip with D-MCs was manually filled with $1.79 \pm 0.21 \mathrm{mg}(\mathrm{n}=54 \mathrm{chips}$, SD) of PVP powder followed by loading ketoprofen into the polymer matrix using $\mathrm{scCO}_{2}$. All chips underwent the same supercritical treatment at $40^{\circ} \mathrm{C}$ and 100 bar for $1 \mathrm{~h}$. The filled D-MCs on chips were visualized using a SEM (Figure 2a, b). The crosssectional X-ray $\mu \mathrm{CT}$ image of the D-MCs loaded with PVP and ketoprofen is shown in Figure 2c. 

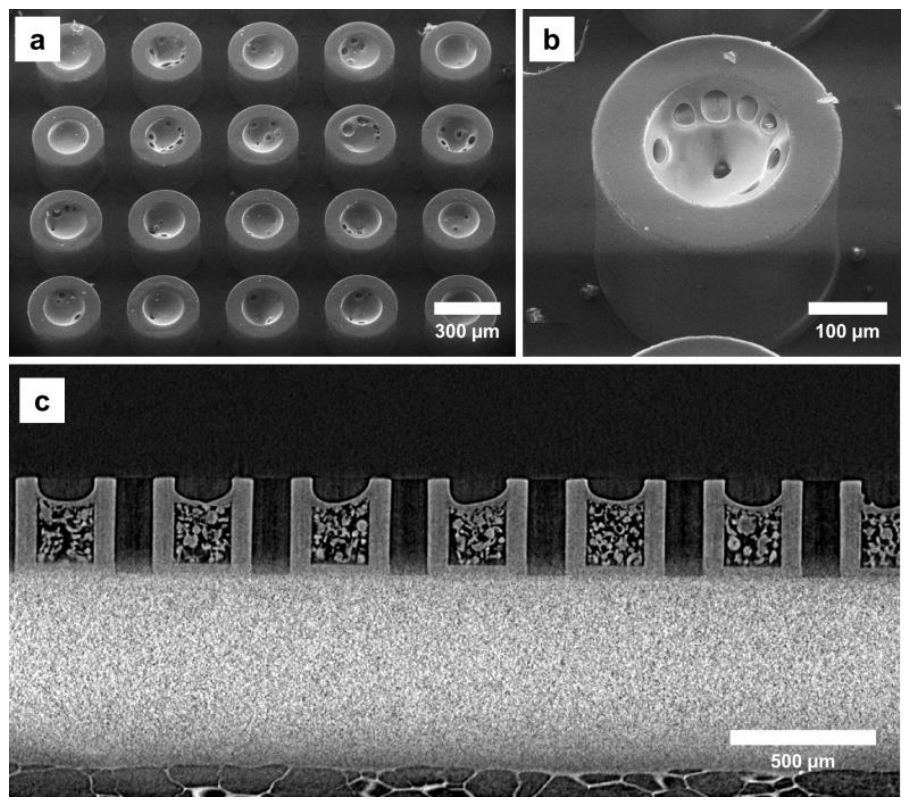

Figure 2: Morphological characterization of drug loaded D-MCs. (a) and (b): SEM images of D-MCs first manually loaded with PVP and then impregnated with ketoprofen in supercritical $\mathrm{CO}_{2}$ at $40{ }^{\circ} \mathrm{C}$ and 100 bar for $1 \mathrm{~h}$. (c): X-ray $\mu \mathrm{CT}$ cross-sectional view of the loaded D-MCs.

\section{Enteric coating deposition onto drug-loaded D-MCs}

The spray coated gastro-resistant lid of Eudragit ${ }^{\circledR}$ L100 was, initially, characterized using contact profilometry to define the coating thickness on two chips. This resulted in thicknesses of $123.0 \pm 1.9$ and $118.7 \pm 3.3 \mu \mathrm{m}$ (SD describes the roughness of the surface of the coating). X-Ray $\mu \mathrm{CT}$ and SEM were utilized to assess the morphology of the coatings after their deposition on the cavity of the D-MCs. The coatings were homogenous (Figure 3a, b) and well distinguishable from the impregnated PVP and ketoprofen (Figure 3c). 

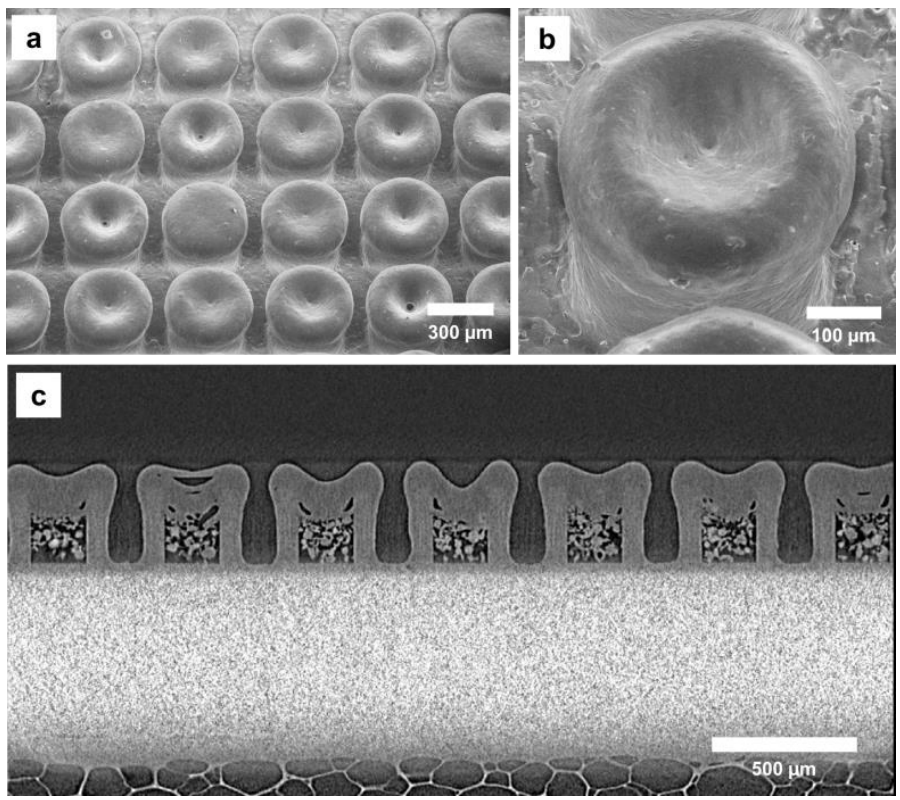

Figure 3: Morphological characterization of loaded and coated D-MCs. (a) and (b): SEM images of D-MCs coated with Eudragit ${ }^{\circledR}$ L100 onto the cavity of the drug-loaded D-MCs. (c): X-ray $\mu \mathrm{CT}$ cross-sectional view of the drug-loaded and coated D-MCs.

\section{In vitro release of ketoprofen from coated D-MCs}

The detachment of the drug-loaded and coated D-MCs from the PAA layer was accomplished by soaking chips in deionized water at $\mathrm{pH} 3.25$ for about $5 \mathrm{~min}$.

The release of ketoprofen was evaluated in human FaSSGF for 120 min (simulating the residence time in the stomach) followed by investigation of the drug release in human FaSSIF for 360 min (simulating the transit time of the small intestine). After $120 \mathrm{~min}$ in FaSSGF, $56 \pm 14 \%$ of the loaded ketoprofen from uncoated DMCs was released compared to $16 \pm 3 \%$ from the coated D-MCs (Figure 4). Upon changing to FaSSIF, a burst release with a significant immediate concentration difference was noticed for the coated microcontainers (p-value $=0.0022$ ). After $6 \mathrm{~h}$ in FaSSIF, $100 \%$ of the loaded ketoprofen was released from both the coated and uncoated D-MCs. The release profile of ketoprofen for the uncoated D-MCs did not present a burst release, but instead followed a first order kinetic. Consequently, statistical significance (pvalue $=0.002$ ) was noticeable for the release of ketoprofen after $2 \mathrm{~h}$ between coated and uncoated D-MCs. The total amount of ketoprofen loaded into a single chip with $625 \mathrm{D}-\mathrm{MCs}$ was $424 \pm 10 \mu \mathrm{g}(\mathrm{n}=14$, SE) corresponding to a weight ratio of ketoprofen to PVP of approximately 1:4 (see the 'Formulation preparation for in vivo and ex vivo studies' section). The total amount of ketoprofen loaded into the coated and uncoated $\mathrm{D}-\mathrm{MCs}$ were seen to be very similar. No significant difference was found ( $\mathrm{p}$-value $=0.2542$ ). 


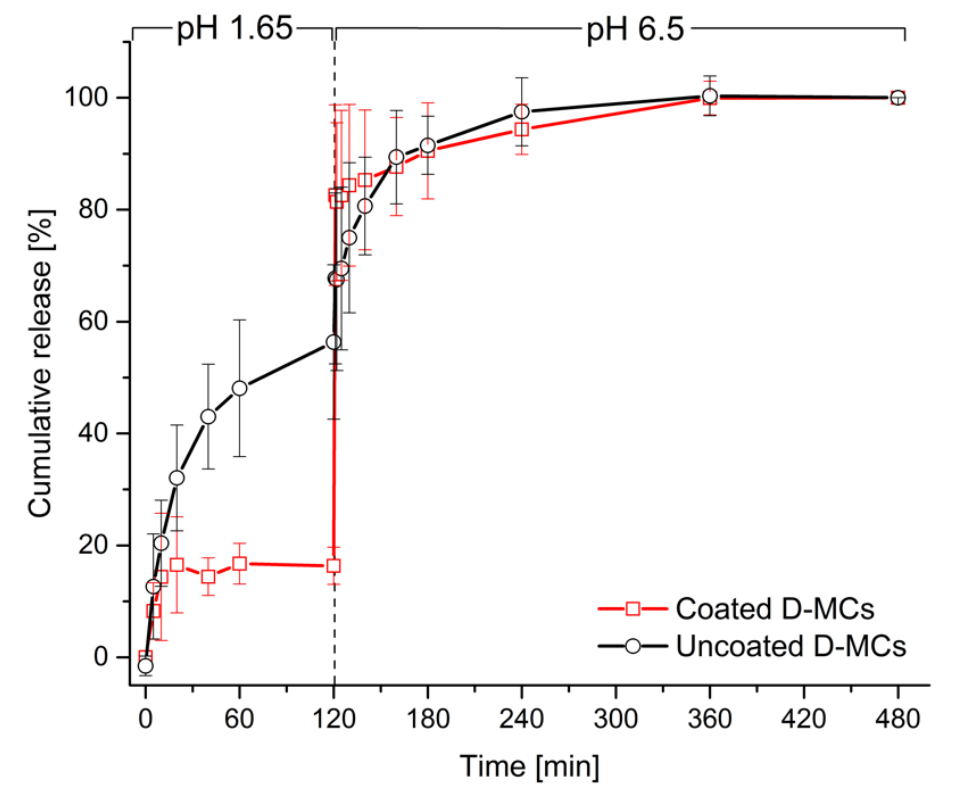

Figure 4: In vitro cumulative release of ketoprofen. Coated (red line) and uncoated (black line) D-MCs. For the first 120 min, the chips were placed in FaSSGF and subsequently in FaSSIF for 360 min. Each release curve is calculated as mean \pm standard deviation $(\mathrm{n}=$ 6 for the uncoated D-MCs, $n=3$ for the coated D-MCs). For the individual profiles refer to Figure S3 in the Supplementary Information.

\section{Solid state characterization of ketoprofen in D-MCs}

The solid state form of ketoprofen in the D-MCs both after $\mathrm{scCO}_{2}$ impregnation and after additional enteric coating deposition was evaluated by means of XRPD. By comparing the diffractograms (Figure 5a), it was found that the distinct peaks of crystalline ketoprofen were not visible in the final $\mathrm{scCO}_{2}$ impregnated and coated microcontainers. This, together with the typical scattering halo (Figure 5a, red), indicated the maintenance of ketoprofen in its amorphous form within the D-MCs. The two controls (coated D-MCs loaded with crystalline ketoprofen and D-MCs with a crystalline ketoprofen:PVP mixture in the ratio 1:4) demonstrated that it was possible to measure through the coating and to detect crystalline ketoprofen in the D-MCs in the same quantity as seen in the $\mathrm{scCO}_{2}$ impregnated and coated microcontainers (Figure 5a, blue and green).

It is worth mentioning that the melted and quenched mixture of ketoprofen:PVP 1:4 (used as control for the in vivo studies) was also found to be amorphous in the XRPD diffractograms (see in Supplementary Information Figure S1).

The XRPD results were corroborated by Raman spectroscopy comparing the spectra of pure crystalline ketoprofen, pure PVP and microcontainers filled with PVP and impregnated with ketoprofen (Figure 5b). As noticeable from the Raman spectra, the characteristic vibrational patterns of ketoprofen were also visible in the impregnated D-MCs. Briefly, the intensity of the peak at $1657 \mathrm{~cm}^{-1}$, which is attributed to the vibrational stretch of the carbonyl $v(\mathrm{C}=\mathrm{O})$, decreased compared to that of crystalline ketoprofen. Moreover, the broadening of the band around $1198 \mathrm{~cm}^{-1}$ ( $\mathrm{CH}$ ring plane bending) together with the lowering of the peak intensities between 1500 $\mathrm{cm}^{-1}$ and $1100 \mathrm{~cm}^{-1}$, supported the hypothesis of ketoprofen amorphization due to the impregnation process ${ }^{29}$. 

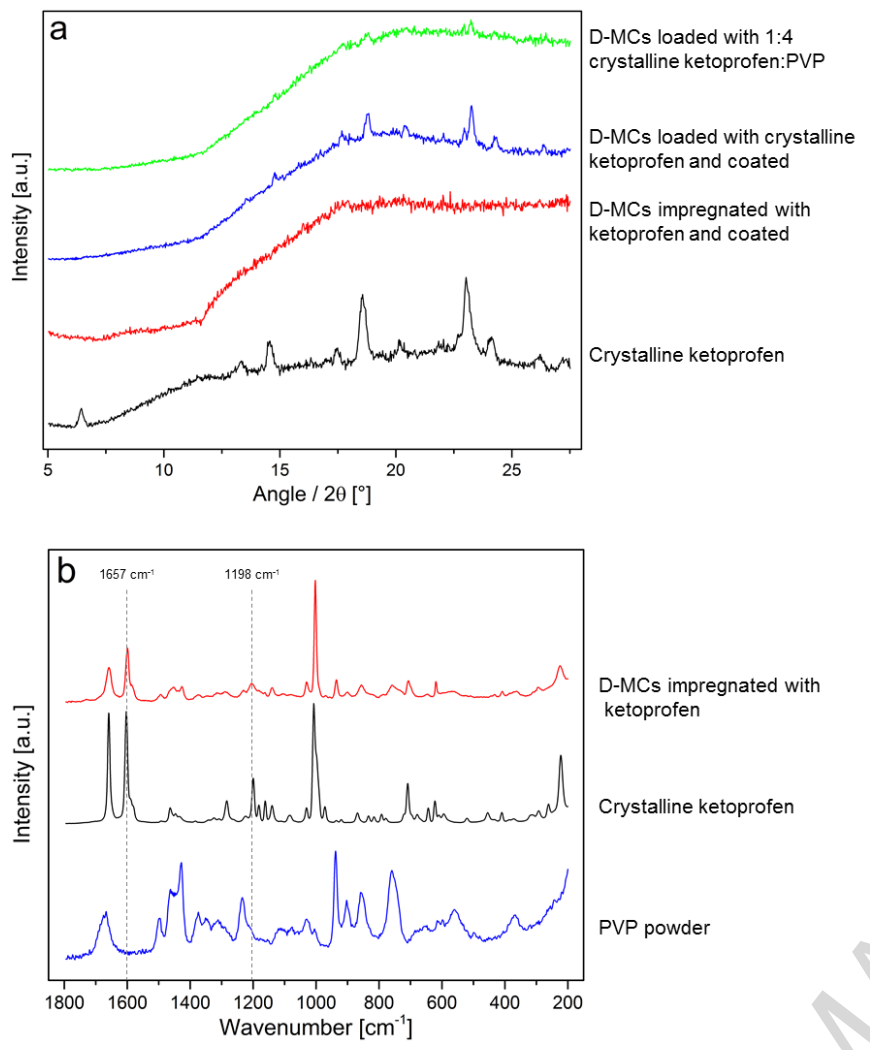

Figure 5: Solid state characterization of ketoprofen in D-MCs. (a) XRPD diffractograms of cry stalline ketoprofen (black), D-MCs impregnated with ketoprofen and coated (red), D-MCs loaded with crystalline ketoprofen and coated (blue) and D-MCs loaded with 1:4 crystalline ketoprofen:PVP (green). (b) Raman scattering profiles of PVP powder (blue), crystalline ketoprofen (black) and D-MCs impregnated with ketoprofen (red).

\section{Formulation pre paration for in vivo and ex vivo studies}

Gelatin capsules were filled with $258 \pm 31(\mathrm{n}=54, \mathrm{SE}) \mathrm{scCO}_{2}$ loaded and coated D-MCs corresponding to $176 \pm$ $14 \mu \mathrm{g}(\mathrm{n}=14, \mathrm{SE})$ of ketoprofen and $741 \pm 52 \mu \mathrm{g}(\mathrm{n}=54, \mathrm{SE})$ of PVP.

$\mathrm{X}$-ray $\mu \mathrm{CT}$ was employed to visualize the microcontainers inside the capsule. It can be seen that the coating was preserved through all preparation steps and that the microcontainers were intact and separated from each other (Figure 6).

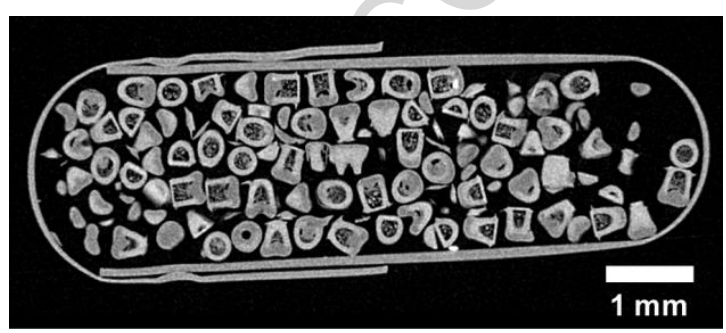

Figure 6: X-ray $\mu \mathrm{CT}$ image of a gelatine capsule filled with loaded and coated D-MCs. 


\section{In vivo studies}

Capsules filled with D-MCs or with the control formulation were dosed by oral gavage to rats. The measured plasma concentration of ketoprofen over time is presented in Figure 7 and key results are summarized in Table 1. The maximum plasma concentrations $\left(\mathrm{C}_{\max }\right)$ are similar for D-MCs and the control. The values were found to be $657 \pm 78 \mathrm{ng} / \mathrm{mL}$ and $488 \pm 105 \mathrm{ng} / \mathrm{mL}$ for the formulation with D-MCs and for the control, respectively (p-value $=0.2191)$. The AUC from 0 to $24 \mathrm{~h}\left(\mathrm{AUC}_{0-24 \mathrm{~h}}\right)$ was calculated to be $406 \pm 40 \mathrm{~min} \bullet \mathrm{ng} / \mathrm{mL}$ for the D-MCs formulation and $320 \pm 49 \mathrm{~min} \bullet \mathrm{ng} / \mathrm{mL}$ for the control, thereby, no significant difference was observed between the two groups $(\mathrm{p}$-value $=0.2041)$. The relative bioavailability from 0 to $24 \mathrm{~h}$ for ketoprofen in $\mathrm{D}$-MCs compared to the control was found to be $127 \pm 23 \%$. However, statistically relevant difference ( $\mathrm{p}$-value = 0.0279) was found for the time corresponding to the maximum plasma concentration $\left(\mathrm{T}_{\max }\right)$ when comparing the two formulations (93 $\pm 17 \mathrm{~min}$ for the $\mathrm{D}-\mathrm{MC}$ and $212 \pm 60 \mathrm{~min}$ for the control). The $\mathrm{AUC}_{0-4 \mathrm{~h}}$ for the $\mathrm{D}$-MCs formulation was $99 \pm 10 \mathrm{~min} \bullet \mathrm{ng} / \mathrm{mL}$ and $55 \pm 18 \mathrm{~min} \bullet \mathrm{ng} / \mathrm{mL}$ for the control resulting in a statistically significant difference between the two groups ( $\mathrm{p}$-value $=0.0387$ ). According to this, the oral relative bioavailability from 0 to $4 \mathrm{~h}$ was $180 \pm 62 \%$ for the $\mathrm{D}$-MC formulation compared to the control. The absorbance rate of ketoprofen $\left(\mathrm{C}_{0}\right.$ to $C_{\max }$ ) for the rats dosed with D-MCs was $10 \pm 2 \mathrm{ng} \cdot \mathrm{min}^{-1} \cdot \mathrm{mL}^{-1}$, which is significantly higher than for the control $\left(4 \pm 1 \mathrm{ng} \cdot \mathrm{min}^{-1} \cdot \mathrm{mL}^{-1}\right)(\mathrm{p}$-value $=0.0430$, Figure 7 , top right $)$.

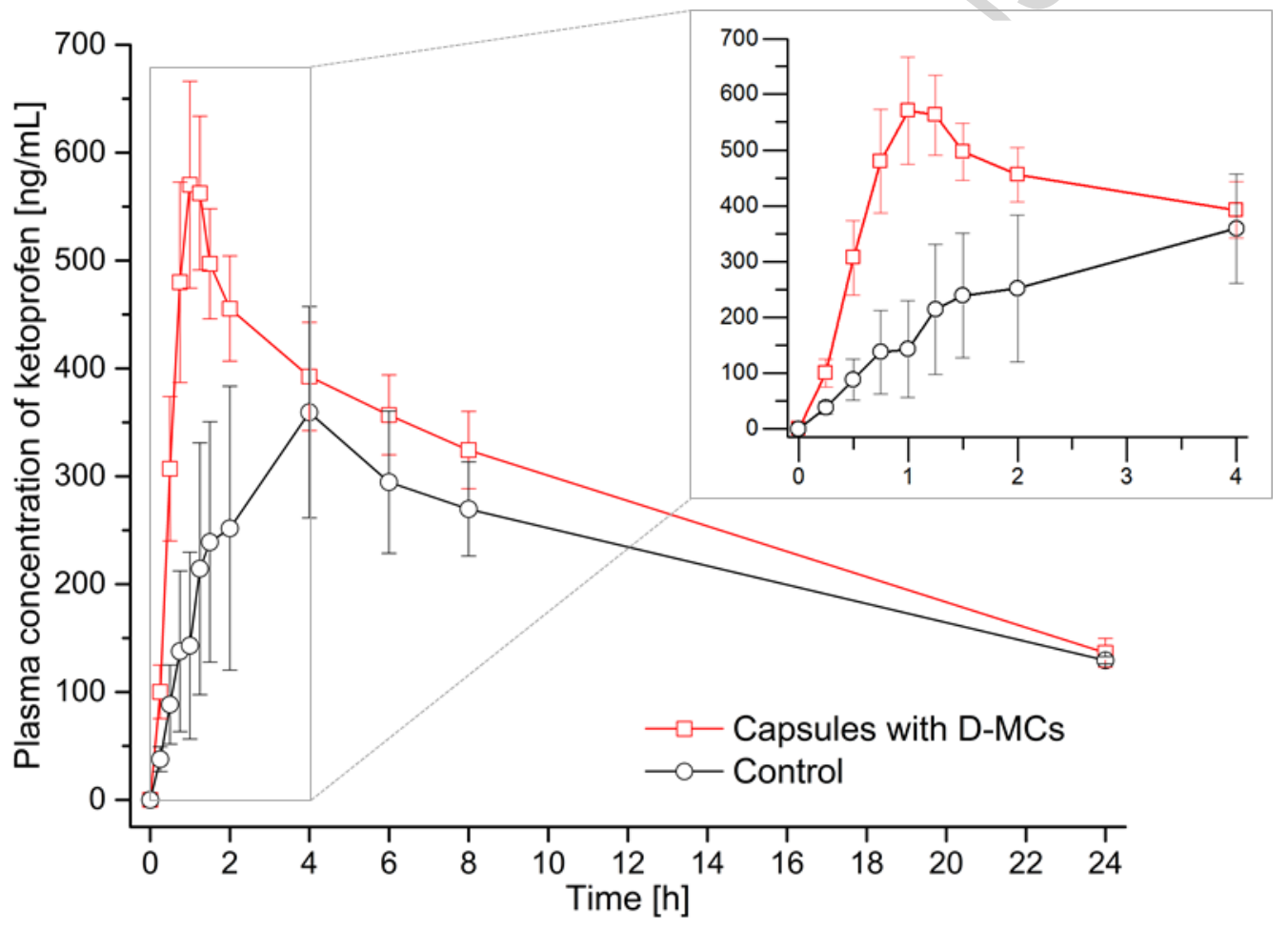

Figure 7: Plasma concentration of ketoprofen over time. (Red line), capsules with loaded and coated D-MCs $(\mathrm{n}=11, \mathrm{SE})$. $($ Black line), control capsules filled with melted ketoprofen and PVP and coated ( $n=6, S E)$. The inset represents the same profiles zoomed in the first $4 \mathrm{~h}$. For the individual profiles refer to Figure S4 in the Supplementary Information. 
Table 1: Non-compartmental model of the in vivo study of ketoprofen in D-MCs $(n=11, S E)$ and for the control formulation $(n=$ 6, SE).

\begin{tabular}{|c|c|c|c|}
\hline & $\begin{array}{c}\text { Capsule with } \\
\text { loaded and } \\
\text { coated D-MCs }\end{array}$ & $\begin{array}{c}\text { Coated capsules with 1:4 } \\
\text { ketoprofen:PVP } \\
\text { amorphous mixture } \\
\text { (control) } \\
\end{array}$ & Effect size $* *$ \\
\hline $\mathrm{C}_{\max }[\mathrm{ng} / \mathrm{mL}]$ & $657 \pm 78$ & $488 \pm 105$ & 0.65 \\
\hline $\mathrm{T}_{\max }[\mathrm{min}]$ & $93 \pm 17^{*}$ & $212 \pm 60^{*}$ & \\
\hline $\begin{array}{l}\mathrm{AUC}_{0-4 \mathrm{~h}} \\
{[\mathrm{~min} \bullet \mathrm{ng} / \mathrm{mL}]}\end{array}$ & $99 \pm 10^{*}$ & $55 \pm 18^{*}$ & \\
\hline $\begin{array}{l}\mathrm{AUC}_{0-24 \mathrm{~h}} \\
{[\mathrm{~min} \bullet \mathrm{ng} / \mathrm{mL}]}\end{array}$ & $406 \pm 40$ & $320 \pm 49$ & 0.68 \\
\hline \multicolumn{4}{|l|}{$\begin{array}{l}\text { Relative oral } \\
\text { bioavailability [\%] }\end{array}$} \\
\hline $0-4 h$ & $180 \pm 62 \%$ & & \\
\hline $0-24 h$ & $127 \pm 23 \%$ & & \\
\hline
\end{tabular}

\section{Ex vivo study}

In order to understand the mechanism of action of the D-MCs, their position in the GI tract of the rats at $\mathrm{T}_{\max }(90$ min) was assessed. No D-MCs were found in the stomach of the rats at $T_{\max }$, whereas many were found in the mid-jejunum (see Figure S2 in the Supplementary Information). This indicates that the enteric coating protected the formulation until the intestine was reached, where the ketoprofen was released and absorbed.

\section{Discussion}

Micro- and nanotechnologies are enabling new possibilities in the world of oral drug delivery. It is a highly complex and multidisciplinary field with focus on fabrication and on the possibilities to integrate novel functionalities into drug delivery systems. In vivo studies proving their actual performances ${ }^{21,30-32}$ are, however, not always carried out.

In this work, an oral DDS based on microcontainers has been further developed compared to previous ones ${ }^{19,33}$. The complete process, starting from the fabrication of the new D-MCs to the loading and coating, highlighting the subsequent results from the in vivo and ex vivo investigations, is presented.

D-MCs were filled with PVP in a simple and reproducible manner and $\mathrm{scCO}_{2}$ was used to load the D-MCs with the model drug ketoprofen with a final 1:4 weight ratio of drug to polymer. A single D-MC has a cavity of $7.5 \pm$ $0.3 \mathrm{~nL}, 178$ times larger compared to other similar $\mathrm{DDS}^{34}$, and each one was loaded with $0.68 \mu \mathrm{g}$ of ketoprofen, which is considerably more compared to the data presented by Chirra et al. $(1.54 \mathrm{ng})^{20}$. The amount of 
ketoprofen in a single D-MC corresponds to $1.3 \% \mathrm{w} / \mathrm{w}$ of the total weight of the microdevice. The technique of $\mathrm{scCO}_{2}$ impregnation was preferred over inkjet printing due to the low spotting reproducibility and low loading capacity of the printing process ${ }^{35,36}$.

In the loading process, $\mathrm{scCO}_{2}$ acts as a solvent for ketoprofen, but not for PVP, which only swells ${ }^{22}$. The porosity of PVP increased during the impregnation allowing ketoprofen to access the D-MCs. $\mathrm{CO}_{2}$, in its supercritical state, has a density similar to a liquid, whereas the viscosity and diffusivity are closer to the ones of a gas. These features are exploited during the impregnation process, where ketoprofen is used in relatively high concentration and diffuses easily with the $\mathrm{CO}_{2}$ into the D-MCs.

During the $\mathrm{scCO}_{2}$ impregnation, a solid state transition of ketoprofen from its crystalline to its amorphous form was obtained. Ketoprofen is a BCS class II drug meaning that it has a poor solubility in water. Therefore, its aqueous solubility can be increased by exploiting the amorphous form ${ }^{37-40}$. The XRPD diffractograms and the Raman spectra (Figure 5a and b, respectively) suggested that the amorphous form of ketoprofen was present after impregnation into the D-MCs, confirming previous results ${ }^{33}$.

Ketoprofen was kept in its amorphous form for at least 7 days (data not shown) due to the use of $\mathrm{scCO}_{2}$ and to its affinity with $\mathrm{PVP}^{29,41,42}$. PVP is a water soluble polymer and has unique properties in prolonging the stability of amorphous forms of drugs, thereby increasing their dissolution rate and solubility ${ }^{41}$. Microcontainers can additionally stabilize the amorphous form of drugs by spatially confining the drug molecules, leading to an improved physical stability of the amorphous drugs ${ }^{16,17}$.

In order to avoid premature release of ketoprofen, D-MCs were coated with the gastro-resistant polymer Eudragit $^{\circledR}$ L100. The in vitro dissolution studies (Figure 4) confirmed that this polymer successfully protected the drug during transit through the gastric environment and dissolved quickly upon arrival in the small intestine (where the $\mathrm{pH}$ is generally above 6$)^{19,43-46}$. Spray coating by an ultrasonic nozzle was selected as the technology to deposit the coating onto the cavity of the D-MCs. The morphology of PVP and ketoprofen after impregnation (Figure 2) was suitable for the coating deposition as there was still space for the coating in the top of the cavity of the D-MCs. The deposition of the lid was simple and straightforward, and has the potential of being scaled up. D-MCs were detached from the fabrication platform by soaking them into acidified water. This approach maintains the integrity of the gastro-resistant lid (Figure 6) and it is a gentler and more controlled procedure than using, for example, mechanical forces. SEM images and X-ray $\mu \mathrm{CT}$ scans of coated D-MCs showed that after spray coating no agglomerates of polymer were present between adjacent microcontainers and that the D-MCs were not attached to each other after dissolution of the PAA sacrificial layer (Figure 3 and 6).

The in vitro release of ketoprofen from the D-MCs in gastric and intestinal simulated media demonstrated the efficacy of the coating. The immediate release of $16 \pm 3 \%$ of ketoprofen from the coated D-MCs in FaSSGF can be explained by the presence of small pores in the coating (Figure 3) and/or the possible variation of the polymer morphology (refer to the video in the Supplementary Information for a more detailed view). For the uncoated DMCs, $56 \pm 14 \%$ of ketoprofen was released in FaSSGF, showing that nothing efficiently hindered the drug release. Coated D-MCs showed a very significant burst release upon changing to FaSSIF due to the dissolution of Eudragit ${ }^{\circledR}$ L100 followed by a fast release of ketoprofen, together with dissolution of PVP (Figure 4).

In vivo studies are necessary when testing new drug delivery systems as they provide indications on possible bioavailability improvements after oral administration compared to a control formulation ${ }^{47,48}$.

The control formulation used in these studies was designed to have the same ratio of ketoprofen:PVP (1:4) and a total amount of drug and polymer as for the D-MCs formulation to obtain information on the behavior of the DMCs. The solid state form of a drug has a large influence on the dissolution rate, and can therefore, be of great importance for the bioavailability ${ }^{49}$. It was found that ketoprofen in the D-MCs after $\mathrm{scCO}_{2}$ impregnation was amorphous and consequently, the ketoprofen in the control formulation was also brought to its amorphous form. This was obtained by melting the ketroprofen together with PVP followed by a fast cooling, which is a common method for preparing the amorphous form of a drug, as reported by Enfalt et $\mathrm{al}^{50}$. 
Compared to the control, the $\mathrm{D}-\mathrm{MCs}$ formulation did not provide a higher $\mathrm{C}_{\max }$. However, a faster $\mathrm{T}_{\max }$ was observed for the D-MCs formulation being roughly 2.3 times faster than the control. This significant difference resulted in a large value for the effect size (Table 1), in accordance with the classification proposed by Choen ${ }^{28}$, where the intervals $0.00-0.20,0.20-0.50$ and $0.50-0.80$ correspond to a small, medium or large effect, respectively. This indicates that $\mathrm{D}-\mathrm{MCs}$ have a large effect on the time of absorption. For the first $4 \mathrm{~h}$ of the plasma concentration-time profile (Figure 7), the absorption of ketoprofen was significantly higher than for the control, again resulting in a large effect size value (Table 1). This difference resulted in a relative oral bioavailability of $180 \pm 62 \%$ for the first $4 \mathrm{~h}$. In accordance with the difference between the $\mathrm{T}_{\max }$ values, the absorption rate was significantly higher for the rats administered with D-MCs compared to the control rats. This supports the conclusion that the D-MCs provided a much faster absorption of ketoprofen compared to the control. It can be hypothesized that this, to some extent, is caused by a faster gastric emptying of the rats dosed with the D-MCs compared to the control. Indeed, D-MCs were most likely released from the gelatin capsule in the stomach as no coating was applied to the entire capsule, conversely to the control formulation. From the plasma concentration curve (Figure 7), it is noticeable that after $4 \mathrm{~h}$ the two formulations show more similar kinetics, and the $\mathrm{AUC}_{0-24 \mathrm{~h}}$ is not significantly different. This is reflected in the relative bioavailability of ketoprofen in the D-MCs formulation compared to the control being $127 \pm 23 \%$. Choi et al. ${ }^{51}$ evaluated the intestinal absorption of a suspension of ketoprofen in rats administering a 2.3 times higher dosage compared to the one used in the present study. The authors report a higher $C_{\max }(6.12 \pm 1.02 \mu \mathrm{g} / \mathrm{mL})$ and a faster $T_{\max }(0.42 \pm$ $0.29 \mathrm{~h}$ ). Indeed, these results might be attributed to the higher dosage and to the fact that ketoprofen was dosed in a suspension form, thus, partially pre-solubilized. An important difference comparing these two studies is the plasma concentration decay over time. The decrease is slower for the D-MCs, indicating a prolonged drug release and absorption time. A possible explanation for this might be provided by the results of our ex vivo study where at the time in which the $\mathrm{T}_{\max }$ was reached $(93 \pm 17 \mathrm{~min}), \mathrm{D}-\mathrm{MCs}$ were spread in the small intestine, and most of them were found in the mid-jejunum embedded deep into the mucus. This pronounced engulfment might indeed have resulted in a slower release and at the same time allowed prolonged absorption of ketoprofen. It has previously been shown in intestinal perfusion studies in rats that SU-8 microcontainers have mucoadhesive properties showing i.e. a high tendency to be engulfed by the mucus ${ }^{19}$.

\section{Conclusions}

In this work, we demonstrated that D-MCs are a promising oral drug delivery system providing a 2.3 times faster $\mathrm{T}_{\max }$ and a $180 \%$ increased $\mathrm{AUC}_{0-4 \mathrm{~h}}$ when compared to the control. These features can be of high importance as it could imply that the administered dose could be reduced. The BCS class II model drug ketoprofen was successfully loaded into D-MCs exploiting the features of $\mathrm{scCO}_{2}$ impregnation maintaining the APi in its amorphous form. Enteric coating was employed to protect the drug from the stomach environment and to release ketoprofen in the intestine, as proven by the in vitro study. All preparation steps are designed to be compatible with each other maintaining ketoprofen in its amorphous state. In vivo and ex vivo analyses finally show the potentials of using D-MCs as an oral drug delivery system.

\section{Acknowledgments}

The authors would like to acknowledge the Danish National Research Foundation (DNRF122) and Villum Fonden (Grant No. 9301) for Intelligent Drug Delivery and Sensing Using Microcontainers and Nanomechanics (IDUN). The 3D Imaging Centre at The Technical University of Denmark is gratefully acknowledged. Line Hagner Nielsen would like to acknowledge Danish Research Council for Technology and Production (FTP), Project DFF 4004-00120B for financial support. The authors would also like to acknowledge Professor Massimo Borelli, School of PhD Programmes, University 'Magna Graecia', Catanzaro, Italy for his suggestion on the statistical analysis. Nanna Bild, Technical University of Denmark, is acknowledged for the drawing of the schematics. 


\section{References:}

1. Thanki, K., Gangwal, R. P., Sangamwar, A. T. \& Jain, S. Oral delivery of anticancer drugs: Challenges and opportunities. J. Control. Release 170, 15-40 (2013).

2. Liu, G., Franssen, E., Fitch, M. I. \& Warner, E. Patient preferences for oral versus intravenous palliative chemotherapy. J. Clin. Oncol. 15, 110-5 (1997).

3. Loh, C. S. et al. Oral versus intravenous administration of 5-aminolaevulinic acid for photodynamic therapy. Br. J. Cancer 68, 41-51 (1993).

4. Mandell, L. A. et al. Sequential antibiotic therapy: Effective cost management and patient care. Can. J. Infect. Dis. 6, (1995).

5. Bossuyt, P. M. M., Dankert, J. \& Speelman, P. Implementation in a Large Teaching Hospital. J. Antimicrob. Chemother. 601-606 (1999).

6. Helander, H. F. \& Fandriks, L. Surface area of the digestive tract - revisited. Scand J Gastroenterol 49, 681-689 (2014).

7. Kararli, T. T. Comparison of the gastrointestinal anatomy, physiology, and biochemistry of humans and commonly used laboratory animals. Biopharm. Drug Dispos. 16, 351-380 (1995).

8. Sjögren, E. et al. In vivo methods for drug absorption - Comparative physiologies, model selection, correlations with in vitro methods (IVIVC), and applications for formulation/API/excipient characterization including food effects. Eur. J. Pharm. Sci. 57, 99-151 (2014).

9. Schmaljohann, D. Thermo- and $\mathrm{pH}$-responsive polymers in drug delivery. Adv. Drug Deliv. Rev. 58, 1655-1670 (2006).

10. Yoshida, T., Lai, T. C., Kwon, G. S. \& Sako, K. pH- and ion-sensitive polymers for drug delivery. Expert Opin. Drug Deliv. 10, 1497-513 (2013).

11. Lovell, J. F. et al. Porphysome nanovesicles generated by porphyrin bilayers for use as multimodal biophotonic contrast agents. Nat. Mater. 10, 324-332 (2011).

12. Jain, S. K., Haider, T., Kumar, A. \& Jain, A. Lectin-Conjugated Clarithromycin and Acetohydroxamic Acid-Loaded PLGA Nanoparticles: a Novel Approach for Effective Treatment of H. pylori. AAPS PharmSciTech 17, 1131-1140 (2016).

13. Restani, R. B. et al. Nano-in-Micro POxylated Polyurea Dendrimers and Chitosan Dry Powder Formulations for Pulmonary Delivery. Part. Part. Syst. Charact. 33, 851-858 (2016).

14. Nagstrup, J., Keller, S., Almdal, K. \& Boisen, A. 3D microstructuring of biodegradable polymers. Microelectron. Eng. 88, 2342-2344 (2011).

15. Marizza, P., Keller, S. S. \& Boisen, A. Inkjet printing as a technique for filling of micro-wells with biocompatible polymers. Microelectron. Eng. 111,391-395 (2013).

16. Nielsen, L. H. et al. Spatial confinement can lead to increased stability of amorphous indomethacin. Eur. J. Pharm. Biopharm. 81, 418-425 (2012). 
17. Nielsen, L. H., Keller, S. S., Boisen, A., Müllertz, A. \& Rades, T. A slow cooling rate of indomethacin melt spatially confined in microcontainers increases the physical stability of the amorphous drug without influencing its biorelevant dissolution behaviour. Drug Deliv. Transl. Res. 4, 268-274 (2014).

18. Nielsen, L. H., Rades, T., Boyd, B. \& Boisen, A. Microcontainers as an oral delivery system for spray dried cubosomes containing ovalbumin. Eur. J. Pharm. Biopharm. (2016). at <http://www.sciencedirect.com/science/article/pii/S0939641116309626>

19. Nielsen, L. H. et al. Polymeric microcontainers improve oral bioavailability of furosemide. Int. J. Pharm. 504, 98-109 (2016).

20. Chirra, H. D. et al. Planar Microdevices for Enhanced In Vivo Retention and Oral Bioavailability of Poorly Permeable Drugs. Adv. Healthc. Mater. 3, 1648-1654 (2014).

21. Fox, C. B. et al. Fabrication of Sealed Nanostraw Microdevices for Oral Drug Delivery. ACS Nano 10, 5873-5881 (2016).

22. Marizza, P., Keller, S. S., Müllertz, A. \& Boisen, A. Polymer-filled microcontainers for oral delivery loaded using supercritical impregnation. J. Control. Release 173, 1-9 (2014).

23. Linder, V., Gates, B. D., Ryan, D., Parviz, B. A. \& Whitesides, G. M. Water-soluble sacrificial layers for surface micromachining. Small 1, 730-736 (2005).

24. Feldkamp, L. A., Davis, L. C. \& Kress, J. W. Practical cone-beam algorithm. J. Opt. Soc. Am. A 1, 612 (1984).

25. Negru, J. et al. High-throughput HPLC method for rapid quantification of ketoprofen in human plasma. Farmacia 63, (2015).

26. Hedges, L. V. Distribution Theory for Glass's Estimator of Effect Size and Related Estimators. J. Educ. Stat. 6, 107 (1981).

27. Sawilowsky, S. New Effect Size Rules of Thumb. Theor. Behav. Found. Educ. Fac. Publ. (2009).

28. Cohen, J. Statistical Power Analysis. Curr. Dir. Psychol. Sci. 1, 98-101 (1992).

29. de Carvalho, L. A. E. B., Marques, M. P. M. \& Tomkinson, J. Drug-excipient interactions in ketoprofen: A vibrational spectroscopy study. Biopolymers 82, 420-424 (2006).

30. LaVan, D. A., McGuire, T. \& Langer, R. Small-scale systems for in vivo drug delivery. Nat. Biotechnol. 21, 1184-1191 (2003).

31. Zhang, W.-J., Hong, C.-Y. \& Pan, C.-Y. Efficient Fabrication of Photosensitive Polymeric Nano-objects via an Ingenious Formulation of RAFT Dispersion Polymerization and Their Application for Drug Delivery. Biomacromolecules acs.biomac.6b01887 (2017). at <http://pubs.acs.org/doi/abs/10.1021/acs.biomac.6b01887>

32. Sant, S. et al. Microfabrication technologies for oral drug delivery. Adv. Drug Deliv. Rev. 64, 496-507 (2012).

33. Marizza, P. et al. Supercritical impregnation of polymer matrices spatially confined in microcontainers for oral drug delivery: Effect of temperature, pressure and time. J. Supercrit. Fluids 107, 145-152 (2016). 
34. Chirra, H. D. \& Desai, T. A. Multi-Reservoir Bioadhesive Microdevices for Independent Rate-Controlled Delivery of Multiple Drugs. 3839-3846 (2012).

35. Fox, C. B. et al. Picoliter-volume inkjet printing into planar microdevice reservoirs for low-waste, highcapacity drug loading. Bioeng. Transl. Med. 9-16 (2017). at <http://doi.wiley.com/10.1002/btm2.10053>

36. Marizza, P., Keller, S. S., Müllertz, A. \& Boisen, A. Polymer-filled microcontainers for oral delivery loaded using supercritical impregnation. J. Control. Release 173, 1-9 (2014).

37. Wlodarski, K. et al. The influence of amorphization methods on the apparent solubility and dissolution rate of tadalafil. Eur. J. Pharm. Sci. 62, 132-140 (2014).

38. Mallick, S. The solid state amorphization of poorly water soluble drugs. Indian J. Pharm. Sci. 66, (2004).

39. Tkalec, G., Pantic, M., Novak, Z. \& Knez, Z. Supercritical impregnation of drugs and supercritical fluid deposition of metals into aerogels. Journal of Materials Science 50, 1-12 (2015).

40. Potter, C. et al. Novel Supercritical Carbon Dioxide Impregnation Technique for the Production of Amorphous Solid Drug Dispersions: A Comparison to Hot Melt Extrusion. Mol. Pharm. 12, 1377-1390 (2015).

41. Yadav, P. S., Kumar, V., Singh, U. P., Bhat, H. R. \& Mazumder, B. Physicochemical characterization and in vitro dissolution studies of solid dispersions of ketoprofen with PVP K30 and d-mannitol. Saudi Pharm. J. SPJ Off. Publ. Saudi Pharm. Soc. 21, 77-84 (2013).

42. Manna, L. et al. Impregnation of PVP microparticles with ketoprofen in the presence of supercritical CO2. J. Supercrit. Fluids 42, 378-384 (2007).

43. Besenhard, M. O. et al. Continuous API-crystal coating via coacervation in a tubular reactor. Int. J. Pharm. 475, 198-207 (2014).

44. Nguyen, D. N., Palangetic, L., Clasen, C. \& Van Den Mooter, G. One-step production of darunavir solid dispersion nanoparticles coated with enteric polymers using electrospraying. J. Pharm. Pharmacol. 68, 625-633 (2016).

45. Sauer, D., Watts, A. B., Coots, L. B., Zheng, W. C. \& McGinity, J. W. Influence of polymeric subcoats on the drug release properties of tablets powder-coated with pre-plasticized Eudragit?? L 100-55. Int. J. Pharm. 367, 20-28 (2009).

46. Nielsen, L. H. et al. pH-triggered drug release from biodegradable microwells for oral drug delivery. Biomed. Microdevices 17, 1-7 (2015).

47. Chirra, H. D. \& Desai, T. A. Emerging microtechnologies for the development of oral drug delivery devices. Adv. Drug Deliv. Rev. 64, 1569-1578 (2012).

48. Sant, S. et al. Microfabrication technologies for oral drug delivery. Adv. Drug Deliv. Rev. 64, 496-507 (2012).

49. Datta, S. \& Grant, D. J. W. Crystal structures of drugs: advances in determination, prediction and engineering. Nat. Rev. Drug Discov. 3, 42-57 (2004).

50. Einfalt, T., Planinšek, O. \& Hrovat, K. Methods of amorphization and investigation of the amorphous 
state. Acta Pharm. 63,305-334 (2013).

51. Choi, J.-S., Jin, M. J. \& Han, H.-K. Intestinal absorption characteristics of ketoprofen in rats. Biopharm. Drug Dispos. 27, 17-21 (2006). 
Graphical abstract

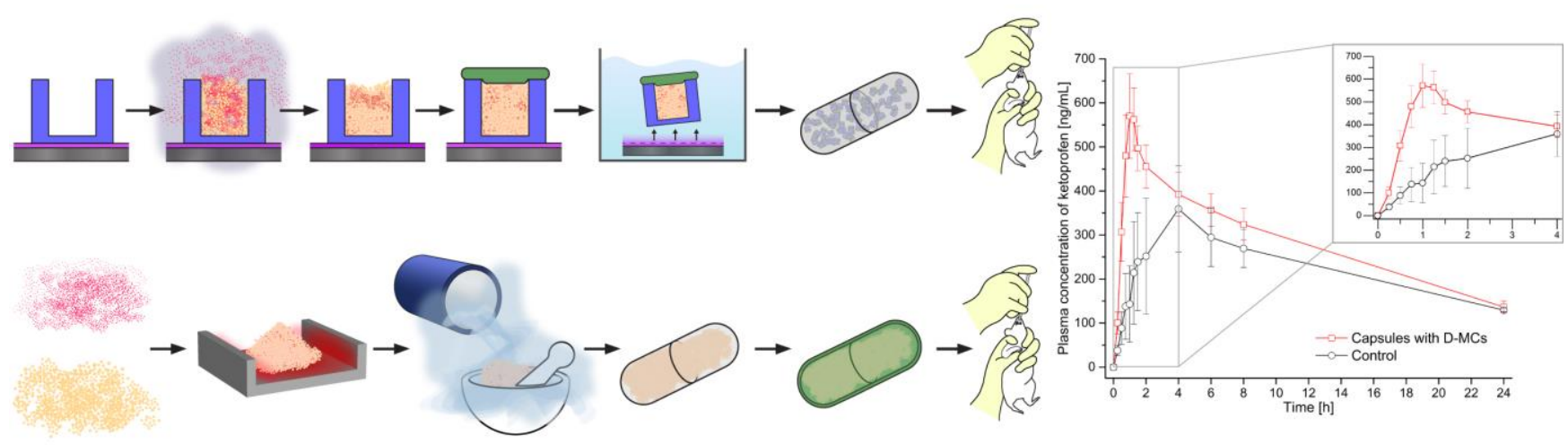

